\title{
Examining the Effect of Students' Early Numeracy Activities at Home on Later Mathematics Achievement via Early Numeracy Competencies and Self-Efficacy Beliefs
}

\section{Sunghwan Hwang*}

\author{
Received \\ Revised \\ Accepted \\ 14 June 2020 \\ DOI \\ August 2020 \\ 11 September 2020 \\ 10.26822/iejee.2020.172 \\ Correspondance Details: Seoul National Universi- \\ ty of Education, Seoul, South Korea. \\ E-Mail: ihwang413@gmail.com \\ ORCID: https://orcid.org/0000-0001-8212-6368
}

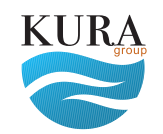

Copyright $@$

www.iejee.com

ISSN: 1307-9298

(C) 2020 Published by KURA Education \& Publishing. This is an open access article under the CC BY- NC- ND license. (https://creativecommons. org/licenses/by/4.0/)

\begin{abstract}
This study aimed to examine the effect of early numeracy activities at home on children's mathematics achievement in fourth grade. It also examined the mediating effects of early numeracy competencies and self-efficacy beliefs in mathematics on this relationship. The study used Trends in International Mathematics and Science Study (TIMSS) 2015 Korean data, selecting nationally representative samples of fourth-grade elementary students $(N=4$ 669) and their parents. A confirmatory factor analysis (CFA) and structural equation modeling (SEM) were used to analyze the study data. The study findings revealed that students who engage in more early numeracy activities at home are more likely to have high mathematics achievement in fourth grade. Early numeracy competencies and self-efficacy beliefs positively mediate this relationship. Moreover, the findings of the study revealed that sequential mediating effects of early numeracy competencies and self-efficacy beliefs on this relationship. Based on the findings of the study, several implications have been proposed.
\end{abstract}

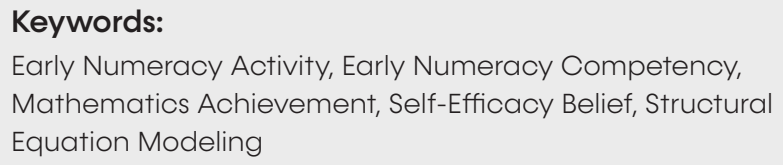

\section{Introduction}

When a baby is born, his/her parents often perform $\checkmark$ various numeracy activities at home. They sing counting songs, read counting books, play with numerical toys, and teach counting and writing numbers. These activities are based on the belief that early numeracy activities at home will positively affect a child's later mathematics achievement in elementary school. However, studies have reported mixed results regarding this relationship. Some inconsistencies have been found in previously conducted studies. Some studies have found a positive effect of early numeracy activities at home on 
later mathematics achievement (Casey et al., 2018; Chiu, 2018; Galindo \& Sonnenschein, 2015; Huang et al., 2017; LeFevre et al., 2009; Niklas \& Schneider, 2017; Zhu \& Chiu, 2019), while others have found a mixed or nonsignificant effect (Blevins-Knabe et al., 2000; Missall et al., 2015; Skwarchuk, 2009; Skwarchuk et al., 2014; Zhang et al., 2020). These inconsistent findings might be because previously conducted studies have not properly considered the effect of a student's background and examined small non-representative samples (Zhu \& Chiu, 2019). Moreover, these studies did not control the effect of preschool learning experiences on mathematics achievement. Therefore, more studies examining how early numeracy activities at home affect mathematics achievement in elementary school students are needed.

Therefore, this study examined the association between early numeracy activities at home on mathematics achievement of fourth-grade students using data obtained from Trends in International Mathematics and Science Study (TIMSS) 2015 in Korea. Participants were selected from nationally representative samples. Moreover, a structural equation modeling (SEM) was utilized to control other variables affecting students' mathematics achievement, including socioeconomic status (SES) (Salihu \& Räsänen, 2018), preschool attendance experience (Anders et al., 2012), and gender (Ganley \& Lubienski, 2016). In doing so, early numeracy competencies and self-efficacy beliefs were considered to mediate variables because when students have high numeracy competencies before entering school, they tend to show high mathematics achievement in elementary school (Aunio \& Niemivirta, 2010; Duncan et al., 2007; Geary et al., 2018; Jordan et al., 2010; LeFevre et al., 2009). The roles of self-efficacy in this process were also examined because students with higher self-efficacy beliefs in mathematics tend to spend more time studying mathematics, resulting in higher mathematics achievement (Bandura et al., 1999; Cleary \& Kitsantas, 2017; Kung \& Lee, 2016; Topçu et al., 2016).

Moreover, we examined whether students' early numeracy competencies and self-efficacy beliefs in mathematics have a mutual effect on the relationship. That is, we evaluated the likelihood of early numeracy competencies and self-efficacy beliefs to sequentially mediate the relationship between early numeracy activities at home and mathematics achievement in school (Hayes, 2017). Students' mathematics achievements at an early stage affect their later achievements, college entrance rate, and profession choices (Ganley \& Lubienski, 2016). Therefore, determining the effect of early numeracy activities at home on mathematics achievement in elementary school and identifying factors that mediate this relationship may help provide educators with guidance on how to improve a student's mathematics achievement. This study examined two research questions: How do early numeracy activities at home relate to mathematics achievement in fourth grade? How do early numeracy competencies and self-efficacy beliefs in mathematics mediate this relationship?

\section{Literature Review}

\section{Early Numeracy Activities, Early Numeracy} Competencies, and Mathematics Achievement

Studies have reported that early numeracy competencies acquired before starting elementary school affect students' later mathematics achievement (Aunio \& Niemivirta, 2010; Chiu, 2018; Duncan et al., 2007; Galindo \& Sonnenschein, 2015; Geary et al., 2018; Jordan et al., 2010; Siegler, 2016; Zhu \& Chiu, 2019). Because early numeracy competencies work as the basis for acquiring new mathematical knowledge in school, students with higher schoolentry numeracy competencies tend to have higher mathematics achievement in elementary school.

For example, Duncan et al. (2007) conducted a meta-analysis with six longitudinal data sets in the U.S., Canada, and the U.K. and concluded that the relationship between school entry mathematics competencies and later mathematics achievement was positively and statistically significant. More specifically, based on Early Childhood Longitudinal Study data examining 21260 U.S. children, the authors reported that the regression coefficient of school-entry numeracy competencies on third-grade mathematics achievement was .53. That is, if school-entry numeracy competency is increased by 1 point, the average thirdgrade mathematics achievement increases by .53 after controlling other variables. Similarly, Jordan et al. (2010) examined the association between numeracy competencies at the beginning of kindergarten and first and third-grade mathematics achievement and found positive associations between them. Additionally, studies on Finland (Aunio \& Niemivirta, 2010), Hong Kong (Zhu \& Chiu, 2019), and Taiwan (Chiu, 2018) reported similar results.

Studies have reported that, among many factors, early numeracy activities at home significantly affect students' early mathematics competencies (Anders et al., 2012; Casey et al., 2018; Huang et al., 2017; LeFevre et al., 2009; Niklas \& Schneider, 2017). Anders et al. (2012) compared the effect of home and preschool learning environments on early numeracy competencies in 532 children in Germany. They found that the association between home learning environments and early numeracy competencies was higher than the 
association between preschool learning environments and early numeracy competencies. Parents are critical socializers in the cognitive development of young children, and their involvement in early numeracy activities helps children acquire basic mathematical knowledge. For example, the study of LeFevre et al. (2009) examining 114 children in Canada found that the frequency of children's engagement in playing board games, card games, roleplaying cooking, and shopping at home was positively associated with their mathematical achievement in a test assessing their understanding of numeration, addition, and subtraction.

Furthermore, some studies have found that formal numeracy activities at home predict student numeracy competency (Casey et al., 2018; Huang et al., 2017; Manolitsis et al., 2013). Studies have reported that parents formally teaching numeracy skills, such as identifying the names of written numbers and instructing their children to count different objects and write down numbers, can predict early numeracy competencies. In sum, students' early numeracy activities at home have been found to work as scaffolding for obtaining formal mathematics knowledge and achieving high numeracy competencies, resulting in high mathematics achievement in elementary school. However, other studies have found mixed and nonsignificant relationships between children's early numeracy activities at home and their mathematics achievement (Blevins-Knabe et al., 2000; LeFevre et al., 2009; Missall et al., 2015; Skwarchuk, 2009; Skwarchuk et al., 2014; Zhang et al., 2020). For example, in a study examining 72 children, Missall et al. (2015) reported no significant relationship between parent-reported mathematical activities and children's mathematics achievement. Similarly, Blevins-Knabe et al. (2000), in a study with 64 children, reported that the association between the frequency of numeracy activities at home and student mathematics achievement was not statistically significant. Moreover, Skwarchuk (2009) examined 25 children and found that some numeracy activities had a positive effect on children's mathematics achievement, while others did not. Zhu and Chiu (2019) suggested two plausible reasons for these inconsistent findings: examining small non-representative samples and omitting home environment variables. Because some studies examined small and non-representative samples (e.g., Blevins-Knabe et al., 2000), it is likely that their participants could not accurately report general phenomena in the relationship between children's early numeracy activities at home and their mathematics achievement.

Furthermore, the studies did not consider the effects of students' home environments (Zhu \& Chiu, 2019). Given that SES background is related to the quality of parental instruction (Galindo \& Sonnenschein, 2015), the outcome of early numeracy activities is likely to differ depending on parents' SES backgrounds. For example, parents with high SES can offer activities with more complex goal structures than parents with low SES (Missall et al., 2015). Consequently, while there is no difference in the range and frequency of numeracy activities offered in families with low and high SES, the complexity of the activities is different (Chiu, 2018).

Early Numeracy Activities, Early Numeracy Competencies, Self-Efficacy Beliefs, and Mathematics Achievement

Self-efficacy beliefs refer to one's beliefs about one's ability to successfully perform a given task (Bandura et al., 1999). Researchers have found that self-efficacy beliefs are critical factors having effect on a student's achievement (Bulut, 2017; Kung \& Lee, 2016; Park \& Jun, 2017). Because students are likely to spend more time and effort on a certain task in which they feel productive, there are positive associations between self-efficacy beliefs and motivation to learn, resulting in high mathematics achievement. The study of Cleary and Kitsantas (2017) examining 331 students in the United States revealed that student self-efficacy beliefs had significant effects on their mathematics achievement. Studies examining Turkish and Korean students have reported similar findings (e.g., Topçu et al., 2016).

Self-efficacy beliefs are developed through the following four sources: mastery experiences, vicarious experiences, verbal-social persuasion, and physiological and emotional arousal (Bandura et al., 1999). Although these sources are all important for creating of self-efficacy beliefs, Bandura et al. (1999) emphasized that mastery experiences are the most critical of these four.

As personal mastery experiences affect people's judgment of their own abilities, experiences affect the interpretation of the other sources. For example, accomplishment in mathematics tasks positively affects personal emotional arousal (Bandura et al., 1999). Moreover, mastery experiences might lead to positive social persuasion from others. Therefore, early numeracy activities with parents at home are likely to help children accomplish various mathematics tasks and improve their numeracy competencies (Casey et al., 2018). These successful mastery experiences then positively affect students' self-efficacy beliefs in mathematics. Consequently, children's early numeracy activities at home are positively associated with their early numeracy competencies and later mathematics achievement through their self-efficacy beliefs in mathematics (Zhu \& Chiu, 2019). 


\section{The Current Study}

Given the inconsistent findings of previous studies examining the relationship between children's early numeracy activities at home and their mathematics achievement, additional studies are needed. Limitations of previously conducted studies require an examination of large samples and the control of more student-related variables (Zhu \& Chiu, 2019). Hence, this study examined the effects of children's early numeracy activities at home on fourth-grade mathematics achievement through their early numeracy competencies and self-efficacy beliefs. TIMSS 2015 Korean student and parent data were used to examine the aforementioned effects. Moreover, students' SES, gender, and preschool learning experience (the period of preschool attendance) were used as control variables to identify the relationships among the study variables clearly. The findings of this study can enhance our understanding of the mechanism through which early numeracy activities at home affect later mathematics achievement in elementary school. Based on the literature review, we developed the following hypotheses. Figure 1 shows the hypothesized path model of the study variables.

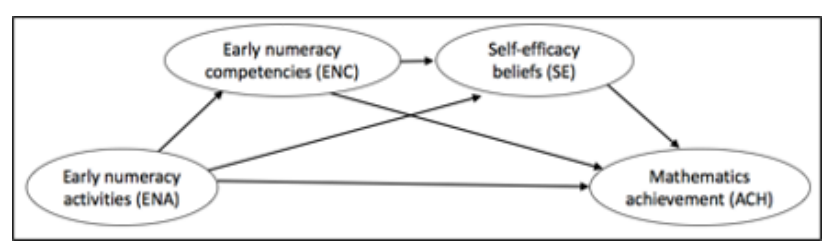

Figure 1. The Hypothesized Path Model of the Study Variables

Hypothesis 1: Children's early numeracy activities at home (ENA) are positively associated with fourthgrade mathematics achievement $(\mathrm{ACH})$ : ENA $\rightarrow \mathrm{ACH}$.

Hypothesis 2: The relationship between children's early numeracy activities at home (ENA) and fourthgrade mathematics achievement $(\mathrm{ACH})$ is mediated by early numeracy competencies (ENC): ENA $\rightarrow$ ENC $\rightarrow \mathrm{ACH}$.

Hypothesis 3: The relationship between children's early numeracy activities at home (ENA) and fourthgrade mathematics achievement $(\mathrm{ACH})$ is mediated by self-efficacy beliefs (SE) in fourth grade: ENA $\rightarrow$ SE $\rightarrow \mathrm{ACH}$.

Hypothesis 4: The relationship between children's early numeracy activities at home (ENA) and fourth-grade mathematics achievement $(\mathrm{ACH})$ is sequentially mediated by early numeracy competencies (ENC) and self-efficacy beliefs (SE) in fourth grade: ENA $\rightarrow$ $\mathrm{ENC} \rightarrow \mathrm{SE} \rightarrow \mathrm{ACH}$

\section{Methods}

\section{Participants}

The Korean TIMSS 2015 data were used to test the study hypotheses. TIMSS researchers collected data from a nationally representative sample with a twostage stratified cluster sample design. They selected representative schools in Korea first, and then randomly selected a fourth-grade class from each school. This study examined elementary students' data, which comprise information on 4669 students (2 411 boys and 2258 girls) from 149 schools. Their parents also participated in a survey.

\section{Measures}

\section{Early numeracy activities at home}

Data on early numeracy activities at home were derived from parents' reports on how often they participated in the following five activities with their children before they began elementary school: (a) say counting rhymes or sing counting songs, (b) play with number toys, (c) count different things, (d) play board or card games, and (e) write numbers. Values on this index range from 1 to 3: often, sometimes, and almost never. After the data were collected, the responses were reverse coded. Hence, higher values indicated more frequent early numeracy activities. The Cronbach's alpha coefficient for early numeracy experiences at home was .788.

\section{Early numeracy competencies}

Data on students' early numeracy competencies before entering school were derived from parents' reports on how much they agreed with the following two indicators: (a) children can do simple addition, and (b) children can do simple subtraction. The two items were binary: No $=0$, Yes $=1$. The Cronbach's alpha coefficient for early numeracy competencies was .757.

\section{Self-Efficacy Beliefs}

Data on students' self-efficacy beliefs were derived from students' reports on how much they agreed with the following four indicators: (a) usually do well in math, (b) math is harder for me than for others, (c) just not good at math, and (d) learn math quickly. The students responded to each statement on a four-point Likert scale ranging from 1 (agree a lot) to 4 (disagree a lot). The responses to items (a) and (d) were reverse coded for this study. Hence, higher values represented a high level of self-efficacy beliefs. The Cronbach's alpha coefficient for self-efficacy beliefs was .842. 


\section{Mathematics achievement}

TIMSS 2015 mathematics assessment contained 179 items with 96 numbers, 59 geometric shapes and measures, and 24 data displays. Because students were asked to solve problems in a booklet with 23 to 29 items, TIMSs provided five plausible values for each student to estimate his/her mathematics achievement scores (Mullis et al., 2016). All five plausible values were used in this study. Based on item-response theory scaling, the overall mean score was 500 , with a standard deviation (SD) of 100

\section{Control variables}

Based on previous studies, the following three variables were controlled: gender, preschool attendance experiences, and SES (Anders et al., 2012; Chiu, 2018; Salihu \& Räsänen, 2018; Zhu \& Chiu, 2019). First, as studies have found a relationship between students' gender and their mathematics performance, gender variable was controlled (Ganley \& Lubienski, 2016). Gender was self-reported by the students with a code 0 for females and 1 for males. The positive coefficients indicated higher scores for male students. Second, preschool experience was controlled. Students learn various mathematics skills from preschool institutions such as kindergarten, and these acquired skills have positively affected students' mathematics performance (Anders et al., 2012). The preschool attendance experience was derived from parents' responses: How long was your child in preschool programs? It was coded as follows: 1 (did not attend), 2 (less than one year), 3 (one year), 4 (two years), 5 (three years), and 6 (four years or more). Third, SES background was controlled. SES background was measured using the following three indicators: (a) fathers' level of education, (b) mothers' level of education, and (c) number of books at home. Parents' levels of education were measured by the highest level of education. Values on this index were measured using an eight-point Likert scale: 1 (did not go to school), 2 (primary or lower secondary), 3 (lower secondary), 4 (upper secondary), 5 (post-secondary), 6 (short-cycle tertiary), 7 (bachelor), and 8 (postgraduate). The number of books at home was derived from students' responses to the question of how many books they have in their homes. Values on this index ranged from 1 (0-10 books) to 5 (more than 200 books). The Cronbach's alpha coefficient for SES was .71.

\section{Data Analysis}

The data at hand were analyzed in two steps. First, a CFA was conducted to examine the fit of the measurement model. Second, an SEM was used to test the hypothesized model of this study (Figure 1).
We used Mplus 8.2 for the analyses using a robust maximum likelihood estimation procedure. Moreover, missing values in the dataset were handled using full information maximum likelihood. As indicated above, student achievement data were reported as five plausible values. Hence, separate data analyses were conducted for each value. Then, we aggregated the results to obtain unbiased estimates. The study used the following indices to determine the validity and model fits: chi-square value, Comparative Fit Index $(\mathrm{CFI})$, Tucker Lewis Index (TLI), and Root Mean Square Error of Approximation (RMSEA). As the chi-square value is sensitive to sample size, we focused more on the other indices. The data fit is acceptable when CFI and TLI are higher than .90, and RMSEA is less than .08 (Kline, 2015).

\section{Results}

\section{Descriptive Statistics and Correlation Analysis}

Table 1 depicts the descriptive statistics of the study, including the mean (M) and SD of all items. Table 2 presents the correlation coefficients between the study variables. The higher the Pearson's $r$ value, the stronger the relationship between two variables (Hayes, 2017). The results revealed that children's early numeracy activities at home had significantly positive relationships with early numeracy competencies, selfefficacy beliefs, SES, and mathematics achievement, ranging from .209 to .279. They did not, however, have a significant relationship with gender and preschool attendance experiences. Early numeracy competencies had a positive relationship with self-efficacy beliefs, SES, preschool attendance experiences, and mathematics achievement, ranging from 041 to .242. Moreover, there was a positive relationship between self-efficacy beliefs and mathematics achievement, with the largest score among all associations $(r=.686, p<.001)$. These results indicate that children's early numeracy activities at home can contribute to the development of high early numeracy competency, self-efficacy beliefs, and mathematics achievement of the students.

\section{Measurement Model Fit}

We implemented CFA to examine the construct validity of the study variables. The CFA results showed an acceptable fit to the data $\left(x^{2}=942.607, d f=77, p<\right.$ $.01, \mathrm{RMSEA}=.049, \mathrm{CFI}=.941$, and $\mathrm{TLI}=.930$ ). All the factor loadings of the latent variables were significant, ranging from .401 to .840 . These results indicated that the construct validity of the scales was acceptable, and all the latent variables were represented well by the indicators. 


\section{Structural Model Fit}

We tested the structural model of this study to examine the direct and indirect relationships between study variables. The results indicated an acceptable fit between the study data and the hypothesized model $\left(x^{2}=946.067, d f=113, p<.01, \mathrm{RMSEA}=.040, \mathrm{CFI}=.952\right.$, and $\mathrm{TLI}=.942)$. The direct, indirect, and total effects results are shown in Table 3 and Figure 2. The standardized path coefficient $(\beta)$ indicates how the outcome change was associated with one SD change in the predictor (Hayes, 2017). For example, a significant coefficient value of 209 (ENA $\rightarrow$ ENC, $\beta=.209$ ) indicates that if there is a unit change in early numeracy activities at home, there is a .209 standard-deviation change in early numeracy competency, with all other variables held constant at their mean.

Table 1. Descriptive Statistics of All Observed Variables

\begin{tabular}{|c|c|c|c|c|c|}
\hline Variable & Item & Short description & M & $S D$ & Cronbach's alpha coefficient \\
\hline \multirow{5}{*}{ 1. ENA ${ }^{a}$} & ENA1 & Say counting rhymes or sing counting songs & 2.304 & .672 & \multirow{5}{*}{.788} \\
\hline & ENA2 & Play with the number of toys & 2.299 & .661 & \\
\hline & ENA3 & Count different things & 2.539 & .587 & \\
\hline & ENA4 & Play board or card games & 2.156 & .681 & \\
\hline & ENA5 & Write numbers & 2.493 & .597 & \\
\hline \multirow{2}{*}{ 2. $\mathrm{ENC}^{\mathrm{b}}$} & ENC1 & Do a simple addition & .95 & .219 & \multirow{2}{*}{.757} \\
\hline & ENC2 & Do simple subtraction & .896 & .305 & \\
\hline \multirow{4}{*}{ 3. $\mathrm{SE}^{\circ}$} & SE1 & Usually, do well in math & 2.821 & .807 & \multirow{4}{*}{.842} \\
\hline & SE2 & Harder for me than for others & 3.087 & .823 & \\
\hline & SE3 & Just not good at math & 2.607 & .838 & \\
\hline & SE4 & Learn math quickly & 2.839 & .841 & \\
\hline 4. Sex & SEX & Sex of student & .517 & .500 & None \\
\hline \multirow{3}{*}{ 5. SES } & SES1 & Father's level of education & 5.939 & 1.493 & \\
\hline & SES2 & Mother's level of education & 5.665 & 1.444 & \multirow{2}{*}{.710} \\
\hline & SES3 & Number of books at home & 3.391 & 1.322 & \\
\hline 6. PRESC ${ }^{d}$ & PRESC & How long the child was in preschool programs & 5.22 & .841 & None \\
\hline \multirow{5}{*}{ 7. $\mathrm{ACH}^{\mathrm{e}}$} & $\mathrm{ACH} 1$ & First plausible values & 607.951 & 67.859 & \multirow{5}{*}{$\begin{array}{r}\text { Scores based on item response } \\
\text { theory }\end{array}$} \\
\hline & $\mathrm{ACH} 2$ & Second plausible values & 608.855 & 67.438 & \\
\hline & $\mathrm{ACH} 3$ & Third plausible values & 608.146 & 66.667 & \\
\hline & $\mathrm{ACH} 4$ & Fourth plausible values & 608.501 & 68.282 & \\
\hline & $\mathrm{ACH} 5$ & Fifth plausible values & 606.721 & 66.692 & \\
\hline
\end{tabular}

aENA: early numeracy activities at home, ${ }^{b} E N C$ : early numeracy competencies, ${ }^{\circ} S E$ : self-efficacy beliefs, ${ }^{d} P R E S C$ : preschool attendance experience, ${ }^{\circ} A C H:$ mathematics achievement.

Table 2. Correlation Coefficients Between Study Variables

\begin{tabular}{|c|c|c|c|c|c|c|c|}
\hline & ENA & ENC & SE & SEX & SES & PRESC & $\mathrm{ACH}$ \\
\hline ENA & 1 & & & & & & \\
\hline ENC & $.209^{\cdots}$ & 1 & & & & & \\
\hline SE & $.234^{\cdots *}$ & $.178^{* *}$ & 1 & & & & \\
\hline SEX & -.017 & .001 & $.101^{\cdots *}$ & 1 & & & \\
\hline SES & $.231^{\cdots}$ & $.068^{\cdots *}$ & $.296^{\cdots}$ & .019 & 1 & & \\
\hline PRESC & .049 & $.041^{\circ}$ & .031 & .01 & -.021 & 1 & \\
\hline $\mathrm{ACH}$ & $.279^{\cdots *}$ & $.242^{\cdots}$ & $.686^{\cdots}$ & $.059^{\cdots}$ & $.488^{\cdots}$ & $.051^{* *}$ & 1 \\
\hline
\end{tabular}

$p<.05, " p<.01, \cdots p<.001$ 
As for indirect effects, the analysis demonstrated that all mediating effects were statistically significant (see Table 4). More specifically, early numeracy activities at home were indirectly and positively related to greater mathematics achievement in fourth grade through early numeracy competencies (Hypothesis 2, ENA $\rightarrow$ ENC $\rightarrow$ ACH; $\beta=.021, p<.001)$ and self-efficacy beliefs in fourth grade (Hypothesis 3, ENA $\rightarrow \mathrm{SE} \rightarrow \mathrm{ACH}$; $\beta=.114, p<.001)$. Furthermore, there were statistically significant sequential mediating effects of early numeracy competencies and self-efficacy beliefs on the relationship between early numeracy activities at home and mathematics achievement (Hypothesis 4, ENA $\rightarrow$ ENC $\rightarrow$ SE $\rightarrow$ ACH; $\beta=.016, p<.001)$. The total indirect effect, the sum of all indirect effects, was statistically significant $(\beta=.151, p<.001)$. Moreover, the total effect of early numeracy activities at home on mathematics achievement in fourth grade was statistically significant ( $\beta=.209, p<.001$ ). That is, when a unit changed in early numeracy activities at home, there was a 209 standard-deviation change in mathematics achievement through early numeracy competencies and self-efficacy beliefs.

Table 3. Standardized Path Coefficients and Standard Errors of Direct, Total Indirect, and Total Effects

\begin{tabular}{|c|c|c|c|}
\hline Path & Total effect & Direct effect & Total indirect effect \\
\hline \multicolumn{4}{|c|}{ Mathematics achievement } \\
\hline $\mathrm{ENA} \rightarrow \mathrm{ACH}$ & $.209(.018)^{\cdots}$ & $.058(.016)^{\cdots}$ & $.151(.010)^{\cdots \cdots}$ \\
\hline $\mathrm{ENC} \rightarrow \mathrm{ACH}$ & $.180(.021)^{\cdots}$ & $.105(.018)^{\cdots \cdots}$ & $.075(.013)^{\cdots}$ \\
\hline $\mathrm{SE} \rightarrow \mathrm{ACH}$ & $.566(.015)^{\ldots *}$ & $.566(.015)^{\cdots}$ & None \\
\hline $\mathrm{PRESC} \rightarrow \mathrm{ACH}$ & $.033(.017)$ & $.033(.017)$ & None \\
\hline $\mathrm{SEX} \rightarrow \mathrm{ACH}$ & $.006(.014)$ & $.006(.014)$ & None \\
\hline $\mathrm{SES} \rightarrow \mathrm{ACH}$ & $.311(.026)^{\cdots}$ & $.311(.026)^{\cdots \cdot}$ & None \\
\hline \multicolumn{4}{|l|}{ Self-efficacy } \\
\hline ENA $\rightarrow$ SE & $.232(.017)^{\cdots \cdot}$ & $.204(.017)^{\cdots \cdot}$ & $.028(.005)^{\cdots \cdot}$ \\
\hline ENC $\rightarrow$ SE & $.135(.023)^{\cdots}$ & $.135(.023)^{\cdots *}$ & None \\
\hline \multicolumn{4}{|c|}{ Early numeracy competencies } \\
\hline ENA $\rightarrow$ ENC & $.207(.021)^{\cdots}$ & $.207(.021)^{\cdots \cdots}$ & None \\
\hline
\end{tabular}

Table 4. Standardized Path Coefficients and Standard Errors of Indirect Effects

\begin{tabular}{llll}
\hline Path & $\begin{array}{l}\text { Indirect } \\
\text { Effect }\end{array}$ & Path & $\begin{array}{l}\text { Indirect } \\
\text { Effect }\end{array}$ \\
\hline ENA $\rightarrow$ ENC $\rightarrow \mathrm{ACH}$ & $.021(.004) \cdots$ & ENA $\rightarrow \mathrm{ENC} \rightarrow \mathrm{SE} \rightarrow \mathrm{ACH}$ & $.016(.003)^{\cdots}$ \\
\hline $\mathrm{ENA} \rightarrow \mathrm{SE} \rightarrow \mathrm{ACH}$ & $.006(.014)$ & Total indirect effect & $.151(.010)^{\cdots}$ \\
\hline${ }_{* * *} \mathrm{P}<.001$ & & &
\end{tabular}

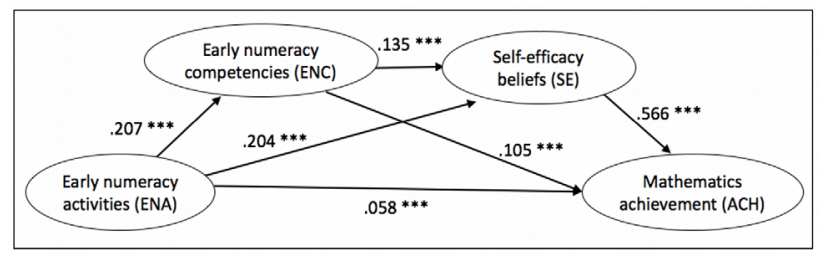

*We used three control variables: student SES, gender, and preschool experience. ${ }^{* * *} p<.001$

Figure 2. The Standardized Direct Relationships

\section{Between Study Variables}

\section{Discussion}

Studies have reported mixed results regarding the relationship between children's early numeracy activities at home and mathematics achievement. Therefore, the primary objectives of this study were to examine the relationship between children's early numeracy activities at home and their mathematics achievement in fourth grade and understand it using two mediating variables better: early numeracy competencies and self-efficacy beliefs in mathematics. The significance of this study is threefold. First, the findings of the study revealed that children's early numeracy activities at home are associated with their later mathematics achievement in elementary school. When children acquire mathematical knowledge through their early numeracy activities at home, they can easily learn new mathematical concepts and procedures that build upon their prior mathematical knowledge. That is, experiencing early numeracy activities at home facilitates the effectiveness of later mathematics learning. This, in turn, results in high mathematics achievement (Galindo \& Sonnenschein, 2015; LeFevre et al., 2009). The results of this study are consistent with studies examining students in the U.S. (Jordan et al., 2010), Canada (LeFevre et al., 2009), Hong Kong (Zhu \& Chiu, 2019), and Taiwan (Chiu, 2018). Moreover, this study expanded existing studies on early numeracy activities by controlling the effects of preschool attendance experiences, which have been neglected in previous studies.

Second, this study evaluated the roles of students' early numeracy competencies and self-efficacy beliefs as mediators in the relationship between their early numeracy activities at home and later mathematics achievement. The study revealed that students' early numeracy activities at home have a positive effect on their early numeracy competencies (i.e., addition and subtraction competencies), and thereby enhance their later mathematics achievement. As students with higher mathematics competency tend to have higher readiness to study mathematics, they can learn advanced mathematical concepts more easily than students with low mathematics competency (Jordan et al., 2010). Moreover, the positive mediating effect of self-efficacy beliefs indicates that early numeracy activities yield high student self-efficacy beliefs in learning mathematics. This may help students continue to study mathematics, resulting in high mathematics achievement (Cleary \& Kitsantas, 2017). Third, this study demonstrated that students' early numeracy competencies and selfefficacy beliefs sequentially mediate the relationship between their early numeracy activities at home and mathematics achievement. This finding is important because previous studies have shown 
that students' early numeracy competencies and self-efficacy beliefs are related and have important implications for understanding student achievement, but no researchers, except Zhu and Chiu (2019), have yet considered how the two function together in a model. Because student mathematical knowledge has cumulative power (i.e., the more they know, the more they can acquire), their early numeracy activities work as the basis for developing early numeracy competencies and positive self-efficacy beliefs in mathematics, and for high mathematics achievement. We extended previous studies by showing that students' early numeracy activities at home are associated with their later mathematics achievement through the mutual effects of their early numeracy competencies and self-efficacy beliefs.

\section{Recommendations}

This study provides valuable insights for educators and parents, aiming to enhance student mathematics achievement. This research shows that students' early numeracy activities at home can have positive effects on their later mathematics achievement because they may help students develop high numeracy competencies and self-efficacy beliefs in mathematics. Therefore, it is important to make parents aware of the value of early numeracy activities at home. Educational programs for parents are effective because they help increase the likelihood that parents will spend more time with their children doing numeracy activities. Such programs may introduce various numeracy activities and teach how to implement them. Moreover, from the educational policy perspective, the government can distribute educational materials (e.g., workbooks, toys, educational tools, and books) to homes with young children. These can help parents easily implement various numeracy activities at home and achieve educational equity because they provide equal learning opportunities for young children regardless of their backgrounds.

Furthermore, educators should help students enhance their self-efficacy beliefs in learning mathematics. The study findings reveal that the association between students' self-efficacy beliefs and their mathematics achievement is the strongest compared to other variables. Teachers can provide students with additional educational materials to support them in developing their self-efficacy beliefs. Furthermore, teachers should ensure that all students experience successful mastery experiences in the mathematics classroom. These endeavors may eventually increase students' commitment to studying mathematics, which may lead to increased mathematics achievement.

\section{Limitations and Future Research}

First, this study relied on self-reported survey data. Although this methodological approach is prevalent in quantitative research, participants may deliberately manipulate the survey and attempt to make a good impression in their responses, such as by depicting themselves as good parents or good students. To overcome this limitation, future research might use other types of data (e.g., observation or video recordings) to validate the findings.

Second, some questions asked for some information from more than four years prior. The adult participants of the TIMSS study were parents of fourth graders, but the TIMSS researchers asked them to respond with information about early numeracy activities at home and early mathematics competence from before their children started elementary school. Previous studies examining a large sample also used the same method (e.g., Chiu, 2018; Zhu \& Chiu, 2019), but these findings may have reliability issues because parents may not remember the information accurately. Hence, a longitudinal study should be conducted to examine the associations more accurately. Third, this study examined only a few study variables. Several factors affect students' mathematic achievement, but this study only examined the effects of students' early numeracy activities at home, early numeracy competencies, and self-efficacy beliefs on their mathematics achievement. Future studies should consider other variables that may contribute to mathematics achievement (e.g., school and teacher variables).

\section{Conclusion}

The findings of this study support the idea that students' early numeracy activities at home increase their later mathematics achievement in elementary school. The study has made a great contribution to the literature examining this relationship by controlling the variables of student gender, SES, and preschool attendance experiences. We also determined that students' early numeracy competencies and self-efficacy beliefs are critical factors in mediating the relationship. Moreover, we found sequential mediating effects of students' early mathematics competencies and selfefficacy beliefs. In sum, students who participate in more early numeracy activities at home are more likely to have high early numeracy competencies and high self-efficacy beliefs, which in turn lead to high mathematics achievement. The study findings shed light on the relationship between students' early numeracy activities at home with parents and their later mathematics achievement through early numeracy competencies and self-efficacy beliefs in mathematics. 


\section{References}

Anders, Y., Rossbach, H. G., Weinert, S., Ebert, S., Kuger, S., Lehrl, S., \& von Maurice, J. (2012). Home and preschool learning environments and their relations to the development of early numeracy skills. Early Childhood Research Quarterly, 27(2), 231-244. https://doi.org/10.1016/j. ecresq.2011.08.003

Aunio, P., \& Niemivirta, M. (2010). Predicting children's mathematical performance in grade one by early numeracy. Learning and individual differences, 20(5), 427-435. https://doi. org/10.1016/j.lindif.2010.06.003

Bandura, A., Freeman, W. H., \& Lightsey, R. (1999). Selfefficacy: The exercise of control. Freeman. https://doi.org/10.1891/0889-8391.13.2.158

Blevins-Knabe, B., Austin, A. B., Musun, L., Eddy, A., \& Jones, R. M. (2000). Family home care providers' and parents' beliefs and practices concerning mathematics with young children. Early Child Development and Care, 165(1), 41-58. https:// doi.org/10.1080/0300443001650104

Bulut, P. (2017). The effect of primary school students' writing attitudes and writing self-efficacy beliefs on their summary writing achievement. International Electronic Journal of Elementary Education, 10(2), 281-285. https://doi. org/10.26822/iejee.2017236123

Casey, B. M., Lombardi, C. M., Thomson, D., Nguyen, H. N., Paz, M., Theriault, C. A., \& Dearing, E. (2018). Maternal support of children's early numerical concept learning predicts preschool and firstgrade math achievement. Child Development, 89(1), 156-173. https://doi.org/10.1111/cdev.12676

Chiu, M. S. (2018). Effects of early numeracy activities on mathematics achievement and affect: Parental value and child gender conditions and socioeconomic status mediation. EURASIA Journal of Mathematics, Science and Technology Education, 14(12), em1634. https:// doi.org/10.29333/ejmste/97191

Cleary, T. J., \& Kitsantas, A. (2017). Motivation and selfregulated learning influences on middle school mathematics achievement. School Psychology Review, 46(1), 88-107. https://doi.org/10.30807/ ksms.2019.22.2.004
Duncan, G. J., Dowsett, C. J., Classens, A., Magnuson, K., Huston, A. C., \& Klebanov, P. (2007). School readiness and later achievement. Developmental Psychology, 43(6), 1428-1446. https://doi.org/10.1037/0012-1649.43.6.1428

Galindo, C., \& Sonnenschein, S. (2015). Decreasing the SES math achievement gap: Initial math proficiency and home learning environments. Contemporary Educational Psychology, 43, 25-38. https://doi.org/10.1016/j.cedpsych.2015.08.003

Ganley, C. M., \& Lubienski, S. T. (2016). Mathematics confidence, interest, and performance: Examining gender patterns and reciprocal relations. Learning and Individual Differences, 47, 182-193. https://doi.org/10.1016/j.lindif.2016.01.002

Geary, D. C., vanMarle, K., Chu, F., Rouder, J., Hoard, M. K., \& Nugent, L. (2018). Early conceptual understanding of cardinality predicts superior school-entry number system knowledge. Psychological Science, 29(2), 181-205. https:// doi.org/10.1177/0956797617729817

Hayes, A. F. (2017). Introduction to mediation, moderation, and conditional process analysis: A regression-based approach. Guilford Publications. https://doi.org/10.1111/jedm.12050

Huang, Q., Zhang, X., Liu, Y., Yang, W., \& Song, Z. (2017). The contribution of parent-child numeracy activities to young Chinese children's mathematical ability. British Journal of Educational Psychology, 87(3), 328-344. https:// doi.org/10.1111/bjep.12152

Jordan, N. C., Glutting, J., Ramineni, C., \& Watkins, M. W. (2010). Validating a number sense screening tool for use in kindergarten and first grade: Prediction of mathematics proficiency in third grade. School Psychology Review, 39(2), 181-195. https://doi.org/10.1080/02796015.2010.12087772

Kline, R. B. (2015). Principles and practice of structural equation modeling (4th ed.). Guilford Publications.

Kung, H. Y., \& Lee, C. Y. (2016). Multidimensionality of parental involvement and children's mathematics achievement in Taiwan: Mediating effect of math self-efficacy. Learning and Individual Differences, 47, 266-273. https://doi.org/10.1016/j. lindif.2016.02.004 


\section{iejee}

LeFevre, J. A., Skwarchuk, S. L., Smith-Chant, B. L., Fast, L., Kamawar, D., \& Bisanz, J. (2009). Home numeracy experiences and children's math performance in the early school years. Canadian Journal of Behavioural Science, 41, 55-66. https://doi:10.1037/a0014532

Manolitsis, G., Georgiou, G. K., \& Tziraki, N. (2013). Examining the effects of home literacy and numeracy environment on early reading and math acquisition. Early Childhood Research Quarterly, 28(4), 692-703. https://doi.org/10.1016/j. ecresq.2013.05.004

Missall, K., Hojnoski, R. L., Caskie, G. I., \& Repasky, P. (2015). Home numeracy environments of preschoolers: Examining relations among mathematical activities, parent mathematical beliefs, and early mathematical skills. Early Education and Development, 26(3), 356-376. https://doi.org/10.1 $080 / 10409289.2015 .968243$

Mullis, I. V. S., Martin, M. O., Foy, P., \& Hooper, M. (2016). TIMSS 2015 international results in mathematics. http://timssandpirls.bc.edu/timss2015/international-results.pdf

Niklas, F., \& Schneider, W. (2017). Home learning environment and development of child competencies from kindergarten until the end of elementary school. Contemporary Educational Psychology, 49, 263-274. https://doi.org/10.1016/j. cedpsych.2017.03.006

Park, S. H., \& Jun, J. (2017). Structural relationships among variables affecting elementary school students' career preparation behavior: Using a multi-group structural equation approach. International Electronic Journal of Elementary Education, 10(2), 273-280. https://doi.org/10.26822/ iejee. 2017236122

Salihu, L., \& Räsänen, P. (2018). Mathematics skills of Kosovar primary school children: A special view on children with mathematical learning difficulties. International Electronic Journal of Elementary Education, 10(4), 421-430. https:// doi.org/10.26822/iejee.2018438132

Siegler, R. S. (2016). Magnitude knowledge: The common core of numerical development. Developmental Science, 19(3), 341-361. https:// doi.org/10.1111/desc.12395

Skwarchuk, S. L. (2009). How do parents support preschoolers' numeracy learning experiences at home? Early Childhood Education Journal, 37(3), 189-197. https://doi.org/10.1007/s10643009-0340-1
Skwarchuk, S. L., Sowinski, C., \& LeFevre, J. A. (2014). Formal and informal home learning activities in relation to children's early numeracy and literacy skills: The development of a home numeracy model. Journal of Experimental Child Psychology, 121, 63-84. https://doi.org/10.1016/j. jecp.2013.11.006

Topçu, M. S., Erbilgin, E., \& Arikan, S. (2016). Factors predicting Turkish and Korean students' science and mathematics achievement in TIMSS 2011. Eurasia Journal of Mathematics, Science and Technology Education, 12(7), 1711-1737. https:// doi.org/10.12973/eurasia.2016.1530a

Zhang, X., Hu, B. Y., Zou, X., \& Ren, L. (2020, January 13). Parent-child number application activities predict children's math trajectories from preschool to primary school. Journal of Educational Psychology. https://doi.org/10.1037/ edu0000457

Zhu, J., \& Chiu, M. M. (2019). Early home numeracy activities and later mathematics achievement: Early numeracy, interest, and self-efficacy as mediators. Educational Studies in Mathematics, 102(2), 173-191. https://doi.org/10.1007/s10649019-09906-6 